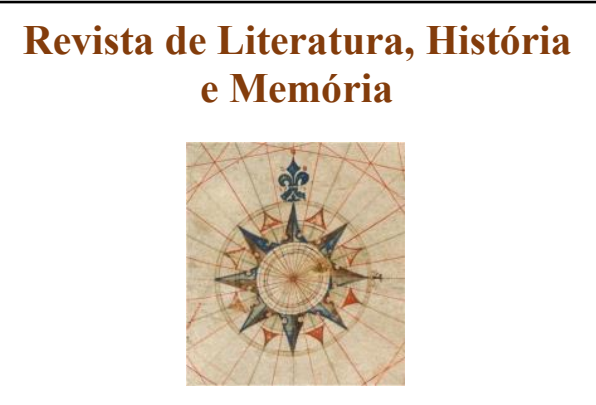

Seção: Pesquisa em Letras no contexto Latino-americano e Literatura, Ensino e Cultura

ISSN 1983-1498

VOL. 17 - No 29 - 2021

U N I O E S T E / CA S C A V E L - p. 245-264

\title{
NOVOS OLHARES PARA ANTIGAS QUESTÕES: APRECIAÇÕES SOBRE A VIDA E A PRODUÇÃO LITERÁRIA DE JOSÉ JOAQUIM DE CAMPOS LEÃO QORPO-SANTO (1829-1883)
}

New insights into old questions: appreciations of the life and literary production of José Joaquim de Campos Lion Qorpo-santo (1829-1883)

\section{Maria Clara Gonçalves ${ }^{1}$}

RESUMO: O escritor gaúcho José Joaquim de Campos Leão (129-1883) produziu entre os anos de 1843 a 1877 um conjunto de variados escritos. Reunidos em 1877, a Ensiqlopédia ou Seis Mezes de uma Enfermidade se estabelece como o projeto literário do escritor, em que constam diversos assuntos transpostos nos mais variados gêneros textuais (poesia, teatro, máximas, etc.). Na obra composta por nove volumes (dos quais apenas seis são conhecidos) percebe-se que Qorpo-Santo procurou criar uma espécie de diário-literário revelador dessa persona santificada e iluminada. $\mathrm{O}$ artigo explora o aspecto literário dessa obra e as escolhas estéticas que utilizou. Além de salientar alguns fatos biográficos, colhidos de diversos documentos, que auxiliam no entendimento de informações presentes na Ensiqlopédia. Dessa maneira, pretende-se trazer novas reflexões para que seja possível compreender de forma mais ampla as singularidades que permeiam esse conjunto de textos e a própria figura do escritor.

PALAVRAS-CHAVES: Qorpo-Santo; Ensiqlopédia ou Seis Mezes de uma Enfermidade; Literatura brasileira oitocentista; Século XIX no Brasil.

ABSTRACT: The gaucho writer José Joaquim de Campos Leão (129-1883) produced between 1843 and 1877 a set of various writings. Gathered in 1877, the Ensiqlopédia or Seis Mezes de uma Enfermidade is established as the writer's literary project, in which there are several subjects transposed in the most varied textual genres (poetry, theater, maxims, etc.). In the work composed of nine volumes (of which only six are known) it is noted that Qorpo-Santo sought to create a kind of literary diary revealing this sanctified and illuminated persona. The article explores the literary aspect of this work and the aesthetic choices he used. In addition to highlighting some biographical facts, gathered from various documents, which help in the understanding of information contained in the Ensiqlopédia. In this way, we intend to bring new reflections so that it is possible to understand more broadly the singularities that permeate this set of texts and the figure of the writer himself.

KEYWORDS: Qorpo-Santo; Ensiqlopédia ou Seis Mezes de uma Enfermidade; Eighteenth century brazilian literature; 19th century in Brazil

O caráter singular dos escritos de José Joaquim de Campos Leão Qorpo-Santo (Triunfo-RS, 19 de abril de 1829/ Porto-Alegre-RS, 01 de maio de 1883) é sempre apontado nos estudos críticos sobre sua obra literária. Esse ponto também resvala para os juízos acerca de sua vida, por isso, inúmeras vezes, os dados biográficos sobressaíram à sua produção

\footnotetext{
${ }^{1}$ Mestre em Literatura e Vida Social (UNESP/Assis) e doutora em Teoria e História Literária (IEL/UNICAMP), com pós-doutorado junto ao Programa de Pós-Graduação em Literatura Brasileira (FFLCH/USP). Pósdoutoranda (PNPD/CAPES) do Programa de Pós-Graduação em Literatura e Vida Social (UNESP/Assis).
} 
escrita. Figura incomum no seu tempo e no atual, Qorpo-Santo transita entre apreciações que ora o encaram como gênio de percepções vanguardistas, ora como um louco que escreveu textos sem significativo valor literário. Os mesmos dizeres sobre sua vida/obra se repetem ao longo do tempo, criando uma narrativa que o levou a ser um escritor mais debatido do que realmente lido. Tanto para os que defendem quanto para os que menosprezam sua obra, há um ponto em comum: a falta de uma leitura atenta de sua produção literária sem se deixar dominar por devaneios biográficos oriundos da intimidade do autor ${ }^{2}$.

Vale destacar que esse interesse pela vida do escritor não foi algo que surgiu espontaneamente. José Joaquim, católico fervoroso, ao incorporar Qorpo-Santo ${ }^{3}$ ao nome, provavelmente inspirado no Frei Pedro González Telmo ${ }^{4}$ - uma espécie de alter ego carregado de ares divinos e com características excêntricas, fez de seu "novo eu" uma figura bastante propositiva em seu contexto social. O mito Qorpo-Santo foi criado pelo próprio, por meio de textos que revelavam seu processo de transformação e/ou notícias sobre as empreitadas ligadas a essa nova condição. Por exemplo, em $O$ Constitucional de 04 de fevereiro de $1873^{5}$ o escritor anunciou um novo comércio de "secos e molhados", cuja finalidade era erguer, em poucos anos, a igreja São José de Leão em uma das montanhas mais altas da cidade - apesar de seus esforços, não há registros da construção da igreja e nem da abertura do comércio. A partir desse novo modo de ser, o pacato cidadão passa a ser reconhecido como um ser portador de uma condição mental desajustada, o que ocasionou inúmeros transtornos em sua vida pessoal e profissional.

Em 1877 concebeu sua peculiar Ensiqlopédia ou Seis Mezes de huma Enfermidade que, ao invés de reunir um conhecimento organizado como o nome sugere, se aproxima de diário-literário com relatos cotidianos, máximas ${ }^{7}$, cartas, artigos escritos para periódicos da

\footnotetext{
${ }^{2}$ Esse texto é fruto da pesquisa de pós-doutorado (PNPD/CAPES) realizado na USP/FFLCH, Departamento de Literatura Brasileira, sob supervisão de João Roberto de Faria, entre 2019 e 2020.

${ }^{3} \mathrm{Em}$ um primeiro momento, o próprio escritor assinava esse novo nome com $\mathrm{C}$ e ao longo dos anos, por conta de sua própria ortografia, mudou para Q.

4 “O Corpo Santo foi a principal devoção marinheira em Portugal entre os séculos XV e XVIII. Trata-se de Frei Pedro Gonçalves, dominicano espanhol que nasceu entre 1180 e 1190, viveu nos conventos de Compostela, Amarante e Tui, morreu à volta de 1246 e está sepultado em Tui, perto do Rio Minho. Em desconhecida acrescentou -se ao nome, o de Telmo, passando a ser conhecido por S. Pedro Gonçalves Telmo, Santelmo ou Corpo Santo" (PEDROSA, 2014, p. 78).

${ }^{5}$ O Constitucional, Porto Alegre, 04 fev. 1873, p. 2.

${ }^{6}$ Todos os volumes estão digitalizados em versão original, no site da Pontifícia Universidade Católica do Rio Grande do Sul (PUCRS): https://biblioteca.pucrs.br/acervos/colecoes-na-biblioteca/acervos-especiais/qorposanto/.

7 "As máximas, enquanto regras subjetivas de conduta, são definidas como principios subjetivos da vontade e têm como objetivo dar prescrições de como devemos agir. Isso significa dizer que uma máxima contém a regra prática determinada pelo sujeito, de acordo com as suas próprias condições, e configura-se, portanto, no princípio pelo qual o sujeito age. As máximas caracterizam-se, também, por conter apenas aqueles elementos
} 
época, laudos médicos, lembranças, poesia, peças de teatro, trechos bíblicos, reflexões sobre a língua portuguesa, etc.

Ressalta-se a particularidade da escrita como uma marca singular dessa coleção. Tendo como referência o "Método Castilho", desenvolvido pelo escritor português Antônio Feliciano de Castilho (1800-1875), Qorpo-Santo concebe uma reforma ortográfica muito particular, na qual as palavras seriam grafadas de acordo com a pronúncia. Para isso, fez algumas reformulações na escrita, a fim de facilitar o processo de aprendizagem. Na Ensiqlopédia, há a transcrição de uma carta do escrito gaúcho à Castilho, na qual elogia o método desenvolvido pelo português e ainda lhe sugere outras ideias que contribuiriam para seu aprimoramento (QORPO-SANTO, volume I, 1877, p. 107). Tendo como base as ideias sobre a língua portuguesa elaboradas por Castilho, Qorpo-Santo elaborou um sistema próprio de conceber o ensino e uso do português, evidenciando as mudanças e os manuseios da sua nova maneira de escrever.

Os textos reunidos foram escritos entre 1848 a 1877 e sua ordenação foge da lógica enciclopédia, obedecendo aos anseios particulares e, porque não dizer, extravagantes do escritor gaúcho. Visto com escárnio por alguns coetâneos ou como um objeto exótico por leitores posteriores, a Ensiqlopédia foi pouco lida em sua integridade. A mescla de textos tão diversos, a diagramação e a linguagem são fatores que dificultam a leitura fluida dessa obra.

A coleção está disposta da seguinte maneira: volume I - composto de duas partes, "Poesia e Proza" e "Prosa"; volume II - "Pensamentos e poemas"; volume III - não encontrado; volume IV - "Romances e comédias"; volume V - não encontrado; volume VI não encontrado; volume VII - constam os dois periódicos do escritor, "A Justiça" e "A Saúde"; volume VIII - "Micelania Qurioza"; volume IX - dividido em quatro partes: "Interpretaçoes: pontos qe parecem qcontraditorios no novo testamento de nosso senhor Jezusqristo"; "Alguns pençamentos esqritos por mim nestes últimos tempos"; "Restos qe qreio, julgo ou pênso não terem sido impreços em algum dos meus oito livros"; e "Introdução (reprodução de livro anterior)".

Apesar da sequência de textos da Ensiqlopédia não obedecer a uma linearidade constante, nota-se, em alguns trechos, um princípio de organização: o volume quatro é dedicado somente ao teatro, já o nono volume possui uma seção sobre "Interpretaçoes: pontos qe parecem qontraditorios no novo testamento de nosso senhor Jezusqristo". No entanto, ao se analisar a obra integralmente, avalia-se que o conteúdo desses textos se torna mais importante 
do que a busca por coerência entre as ideias apresentadas e sua sequência. O que parece mais indispensável, ainda, é que as informações presentes nessa obra auxiliam no entendimento do processo de criação da persona Qorpo-Santo:

Os trambulhões em que tenho vivido desde 1864 julho, até o prezente 1875 Septembro - obrigam-me a publicar o que hei escripto desde Julho de 1862 sem ordem quanto as dactas sem distinção do que produzi antes de assignarme Corpo-Santo, e depois assigno este nome: sem dividir completamente - proza, de verso como pretendia. O farão meus filhos, se tiverem gosto para estas couzas (QORPO-SANTO, 1877, volume I, p. 130).

Mesmo com a intenção de ordenar todos os seus textos, Qorpo-Santo mostra-se consciente de que resolveu imprimi-los a despeito dos infortúnios de sua vida. Ou seja, a necessidade de publicar sua obra torna-se maior do que qualquer organização (ou a falta dela): "Se os pensamentos izolados se não - podem qualificar - um trabalho literario; reunidos podem" (QORPO-SANTO, volume II, 1877, p. 17). O interesse em divulgar suas ideias sobrepõe o formato que elas deveriam ter. Obviamente, há uma preocupação com a maneira pela qual seus pensamentos seriam transmitidos, mas isso não inviabilizou sua publicação.

Nota-se, pelo primeiro nome dado ao conjunto de textos, que Qorpo-Santo quis escrever uma enciclopédia no sentido convencional, em que constasse um conhecimento organizado sobre assuntos pertinentes. Porém, o segundo título demonstra que nesses livros também há outros tipos de textos, que se relacionam a uma ordem mais íntima e próxima a um estado de incômodo. Esse conjunto de escritos que se configuram como um diárioliterário, expondo os anseios pessoais do escritor juntamente com suas produções literárias.

As informações sobre quantos volumes foram impressos e como ocorreu a distribuição desse material são imprecisas. Na capa do segundo volume consta o preço de $5 \$ 000$ (cinco mil réis); porém, há indicação de que publicou toda sua obra gratuitamente: "Publiquei todas as minhas obras - gratuitamente" (Ensiqlopédia, volume II, 1877, p. 49). Sabe-se, no entanto, que esses livros obtiveram uma pequena circulação na época e posteriormente ficaram no anonimato até serem (re)descobertos no século XX.

A produção dramática, conjunto de textos que trouxe o reconhecimento ao escritor, faz parte do quarto volume do Ensiqlopédia. Por meio desta coleção que a obra literária qorposantense se propagou e adentrou os espaços artísticos do século XX. Ignorado pelos letrados do XIX, no século seguinte esses textos tornaram-se objetos instigantes, já que não obedeciam a critérios estéticos de fácil assimilação. As peças de teatro de Qorpo-Santo mesclavam elementos das mais variadas ordens, ocasionando uma dificuldade de encaixá-la a apenas um 
só tipo de gênero dramático.

Os estudos críticos mais afamados que se debruçaram sob o teatro de Qorpo-Santo conferiram pouca atenção a sua ligação com a Ensiqlopédia e o leram como algo que estivesse apartado desses outros escritos. Essa produção dramática foi analisada, em diversos estudos, a partir de procedimentos modernos que a deslocaram da cena cultural na qual foi concebida. Em um primeiro momento, essa leitura entusiasmada, posicionou o escritor como um artista genial e fora de seu tempo. Passado o frenesi inicial, a recepção acalorada cedeu lugar a análises que procuravam entender sua dramaturgia dentro de diretrizes mais próximas ao momento em que foram concebidas. Nos caminhos dessa curiosa recepção, encontram-se as barreiras que o próprio texto de Qorpo-Santo coloca, visto que a mescla de interesses, gêneros e dizeres, cria uma produção dramática que navega por diferentes lugares sem se atracar a nenhum.

Ocorre algo semelhante na Ensiqlopédia, em que a variedade de textos e assuntos frustra uma leitura que tenta organizar o material e enquadrá-lo dentro de uma chave fechada. A forma de composição dessa coleção sugere que a disposição do texto não tem o mero propósito de transmitir informações e referências (como se espera de uma enciclopédia comum), mas atende a um princípio de organização muito particular, possivelmente orientado pela intenção de gerar efeitos de surpresa e estranhamento; efeitos, em alguma medida, artísticos, o que permitiria a leitura dessa obra como algo semelhante a uma obra literária.

Nesse conjunto de textos, depara-se com alternância de escritos de natureza distinta a partir de cortes abruptos (depois de um poema pode vir um artigo de jornal ou uma receita culinária), que geram a impressão de disparidade e gratuitismo, permitindo associar a obra à condição mental de Qorpo-Santo. Em outras palavras, as particularidades da Ensiqlopédia fazem com que pese sobre a obra o estigma da loucura. Tais traços distintivos, contudo, antes de afastarem as criações de Qorpo-Santo da literatura legítima, parecem atestar seu aspecto literário. Com efeito, Foucault reconhece que "entre a loucura e a obra, a linguagem é o lugar vazio e pleno de sua mútua exclusão, é a linguagem que transgride os limites da razão, que permite construir uma obra que é, ao mesmo tempo, ausência de obra" (FOUCAULT apud MACHADO, 2005, p. 45-46). Isso permite inferir que a própria linguagem artística, por estar prenhe de singularidades e dotada de lógica e organicidade únicas, subverte os modelos lógicos e racionais comuns. Ao fugir da enunciação de referências imediatas (como ocorre nos textos não artísticos), a linguagem da literatura se assume como universo relativamente autônomo, discurso de exceção frente aos discursos racionais. É nesse ponto que loucura e literatura se aproximam. Desse modo, quando se trata da criação literária de um autor que foi 
julgado como "louco", os limites entre intencionalidade artística e os efeitos de uma condição mental particular são difíceis de serem definidos, e, de certo modo, a busca em estabelecer tais limites surge como obstáculo à interpretação da obra.

Seja motivada por loucura ou intenção artística, a Ensiqlopédia surge como obra dotada de uma disposição particular que resiste à interpretação reducionista reputando sua natureza e estrutura à condição de mero produto de delírios. Pode-se dizer que os textos presentes nesse conjunto (poesia e teatro, por exemplo) devem ser compreendidos para além da suposta loucura do escritor, visto que, apesar de a linguagem de Qorpo-Santo poder estar associada ao seu "estado de alienação", o espaço literário permite que a linearidade instável de seus textos e/ou suas ideias fragmentárias façam sentido dentro de sua obra:

Na literatura não há encontro absoluto entre a obra e a literatura. A obra jamais encontra seu duplo finalmente dado. Por isso, ela é a distância que há entre a linguagem e a literatura, uma espécie de espaço de desdobramento. Esse espaço especular é o que se poderia chamar simulacro (FOUCAULT, 2005, p. 147).

Salienta-se a relação entre a literatura e a loucura, pois a leitura da obra de Qorpo Santo, exclusivamente sob o prisma de sua condição mental, está sujeita a equívocos. Por exemplo, a consideração dos escritos de Qorpo-Santo como resultado de sua compulsão pela escrita, reconhecida pelos médicos de seu tempo, pode sugerir o automatismo e mesmo a displicência de seu processo criativo. Não há como negar que o desequilíbrio mental de Qorpo-Santo afetou, em alguma medida, sua escrita e sua vida como um todo, já que, ao ter sido considerado um "alienado", perdeu o prestígio dentro da sociedade gaúcha, passando de um respeitado professor a uma figura depreciativamente extravagante, e muitos de seus escritos, inclusive os literários, testemunharam essa condição. Contudo, entender quais eram os reais sintomas dessa alienação ou como seu comportamento mudou depois da doença. Ou ainda, o que em seus escritos é oriundo de suas idiossincrasias mentais e o que era programado, encerra questões difíceis de serem respondidas, visto que não há muitas informações sobre esse aspecto da vida do escritor, a não ser os laudos que constam na própria Ensiqlopédia.

Os escritos de Qorpo-Santo, assim, parecem filiar-se a uma orientação insubmissa a modelos e, considerando-se tanto o título que os enfeixa, quanto seu conteúdo, constata-se haver na obra a reiteração de temas e certa unidade de assuntos que traduzem senão uma visão integrada, ao menos trazem fortes traços de unidades do pensamento. As produções dramáticas veiculam situações cômicas absurdas, com um conteúdo sentencioso e revestido 
por clara orientação moral. Já nos outros textos há as impressões particulares da sua vida, como aspectos de sua condição mental e de seu meio social.

Em suma, a despeito da forma singular com que se organiza e do lastro cômico que permeia muitos de seus escritos, a Ensiqlopédia parece conter uma intenção de contribuir para o melhoramento da sociedade por meio da escrita e difundir ideias, consideradas por QorpoSanto, úteis e até edificantes. Essa intenção talvez leve o escritor a tratar o conjunto de seus textos como obra de um espírito ilustrado - daí, possivelmente, lhe vem a sugestão de nomeálos como uma enciclopédia, em referência aos importantes trabalhos filosóficos da França iluminista.

A Enciclopédia começou como um produto de luxo limitado principalmente à elite da corte e da capital. Mas depois de assumir uma forma mais modesta e de seu preço baixar até as possibilidades da classe média, ela se disseminou pela bourgeoisie d'Ancien Régime, uma burguesia que vivia de rendas, cargos públicos e serviços, e não da indústria ou do comércio. A burguesia capitalista moderna também tinha poder aquisitivo à altura da Enciclopédia, e alguns comerciantes esclarecidos de fato a compraram, porém foram tão poucos que se tornam insignificantes em comparação com os privilégiés e profissionais liberais, que adquiriram a maioria das cópias (DARTON, 1996, p. 406).

Apesar de muitas das ideias iluministas não estarem consonantes às de Qorpo-Santo enquanto a corrente filosófica defendia o liberalismo, o pensamento amparado pela razão, o não absolutismo etc., escritor brasileiro era conservador, monarquista, possuía um pensamento amparado em ideais religiosos de orientação católica etc. A Enciclopédia dos iluministas franceses parece ter sido tratada como modelo de obra dotada de dignidade intelectual, já que está entre os livros formadores do modelo de sociedade esclarecida, valorizada nos oitocentos, tendo contado com grande circulação no mercado editorial internacional e brasileiro no século XIX. Além disso, alguns princípios iluministas associam-se à maçonaria, associação à qual Qorpo-Santo esteve vinculado.

Dentre as referências que ajudam a configurar os escritos da Ensiqlopédia, destaca-se Mariano José Pereira da Fonseca, o Marquês de Maricá (1773-1848). Figura de pouco relevo na história literária brasileira, foi autor de Máximas, pensamentos e reflexões, publicada pela primeira vez em 1843, financiada pelo próprio autor e distribuídas gratuitamente - talvez qualquer semelhança com Qorpo-Santo e sua Ensiqlopédia não seja mera coincidência. O livro obteve um certo reconhecimento na época, visto que o moralismo literário, tema da obra, era algo inédito na literatura brasileira até aquele presente momento. Porém, apesar do ineditismo da produção literária do Marquês de Maricá, suas máximas eram leigas e com 
sentenças morais simplórias. O crítico José Veríssimo que dedicou algumas linhas ao Marquês de Maricá em sua História da Literatura Brasileira, enaltece seu mérito pelo protagonismo, mas reconhece a trivialidade de seus escritos. Como um legítimo criador "da filosofia do lugar-comum”, segundo Wilson Martins (REMOR, 1996, p.14), Maricá pode não ter agradado os críticos modernos, mas tornou-se uma inspiração à Qorpo-Santo.

Em contrapartida, José Veríssimo registra, em Maricá, a ausência de uma linha filosófica peculiar ou "sequer alheia afeiçoada pela sua própria experiência e meditação", limitando-se a repetir "lugares-comuns da ética contemporânea" e mesclando princípios do "cristianismo sentimental" com o "liberalismo político". Enfatiza, de um lado, "a falta de finura, penetração ou originalidade"; e de outro, a possibilidade de "ser leitura agradável e proveitosa, porque o essencial é são e a forma escorreita, sem rebusca indiscreta de purismo e já do nosso tempo e gosto." Avalia as máximas de Maricá como fazendo parte da "vulgar sabedoria", sem os dons singulares de expressão dos grandes modelos franceses, La Rochefoucauld e Vauvenargues. Nem por isso, segundo ele, as suas máximas perdem a importância de "primeiro exemplar do moralismo leigo e literário de nossa literatura". (REMOR, 1996, p.13).

O escritor gaúcho cita o nome de seu afamado autor em várias passagens da Ensiqlopédia, transcrevendo um trecho de Máximas, pensamentos e reflexões no volume I, em que o Marquês afirma que a sabedoria seria encontrada por meio do estudo da natureza. Intrigado com tal afirmação, Qorpo-Santo envia uma carta ao autor, pedindo que este lhe ensine o método para que extraísse a sabedoria da natureza. A carta foi enviada, mas sua resposta, caso tenha ocorrido, não foi transcrita. De qualquer modo, essa obra serviu como um modelo às sentenças morais do escritor gaúcho, como quando afirma "Tenho convertido em amigos - muitos de meus maiores inimigos. (QORPO-SANTO, 1877, volume I, p. 151), notase a inspiração vinda de Maricá que pontua "2214 - Conquistai os vossos inimigos com benefícios, e os tereis sujeitos e amigos por gratidão" (MARICÁ, 1839).

Não obstante, nas máximas de Qorpo-Santo há uma alternância entre regras de conduta e sentenças banais ou chistosas. Essa quebra no tom do discurso, cria momentos de comicidade. Ou seja, a própria organização entre um texto de estilo grave e outro mais despojado, provoca um efeito risível, que se origina na ruptura do tema do discurso que estava sendo apresentado. Ao pontuar que "Entre muitas couzas inúteis: achão-se sempre muitas úteis" (QORPO-SANTO, 1877, volume I, p. 115), o escritor elabora uma oração subordinada explicativa aos moldes de uma máxima, mas o ensinamento é inexpressivo e pouco elaborado.

A banalidade de tais sentenças lembra as construções do Barão de Itararé personagem criado pelo jornalista Aparício Torelly (1895-1971) e conhecido por suas 
afirmações (estruturadas de maneira próxima as máximas) engraçadas - seja pela ausência de profundidade, excesso de clichês ou trocadilhos. Por exemplo, em "Uma boa costureira nunca deve perder a linha" (TORELLY apud REMOR, 1996, p. 109), a sentença do Barão de Itararé constrói-se como um trocadilho risível que faz um paralelo entre um artigo central da costura e uma conduta moral apropriada. Utilizando a palavra "linha", que está disposta tanto como um objeto fundamental na costura quanto como a alusão de se manter dentro da ordem social, o autor sentencia que a "boa costureira" não deve perder a "linha" em nenhuma dessas duas significações. Qorpo-Santo, em outro trecho de sua coleção, também elabora um trocadilho cômico, em que o efeito é claramente captado ao pontuar que a similaridade entre as palavras bule e burro pode provocar uma disparatada confusão ${ }^{8}$ : "Bule branco, e burro branco, muitas vezes - confunde-se!" (QORPO-SANTO, 1877, volume I, p. 169).

$\mathrm{Na}$ Ensiqlopédia são citadas, ainda, outras referências literárias que ajudam a compreender os gostos de Qorpo-Santo. Cita-se Antônio Vieira (1651-1725), reconhecido autor de inúmeros sermões em que se destacavam um estilo conceptista, há um trecho da coleção que evidencia o apreço do escritor gaúcho às críticas feitas pelo padre barroco a determinadas instâncias públicas. Além de um excerto da tragédia Othelo de Jean-François Ducis, traduzida por Gonçalves de Magalhães, uma das peças mais encenadas no século XIX, permite entender uma das fontes teatrais que Qorpo-Santo utilizou para engendrar sua dramaturgia. "O furacão prediz a tempestade/ Mas a mulher, oh céo! pérfida e calma/ Nos embebe o punhal, e nos afaga!” (QORPO-SANTO, 1877, volume I, p. 108-109), a reprodução da fala da personagem Othelo dá subsídios para traçar uma analogia entre a peça de QorpoSanto, Eu sou vida; Eu não sou morte, e Othelo9.

Partindo para outros assuntos, os relatos cotidianos de Qorpo-Santo transcritos nesse conjunto de textos, evidenciam aspectos que levam o leitor a instâncias íntimas, estabelecendo um tom de diário aberto ao público. A descrição de determinados hábitos alimentares, de sonhos ou de lembranças abre um espaço pessoal e coloca a figura do escritor mais próxima aos leitores: "15 dias quazi excluzivamente de ovos alimentando, originou-me algumas feridinhas nas maõs; passar-me-ei para leite" (QORPO-SANTO, 1877, volume I, p. 150). Seu processo de conversão também ganha destaque nesses relatos, em que demonstra como

\footnotetext{
8 [...] o jogo de palavras nos faz mais pensar num descuido da linguagem, que se esqueceria por um momento de sua destinação verdadeira e pretenderia então regrar as coisas de acordo consigo mesma, em vez de se regrar de acordo com as coisas. O jogo de palavras denuncia, portanto, uma distração momentânea da linguagem e por isso, aliás, é engraçado. (BERGSON, 2007, p. 90- 91)

${ }^{9}$ Assunto explorado nesse artigo: GONÇALVES, Maria Clara. Revisitando a dramaturgia de Qorpo Santo em seu contexto original. Sala Preta, São Paulo, v. 18, n. 1, p. 168-180, 2018. Disponível em: http://www.revistas.usp.br/salapreta/article/view/138390. Acesso em: 31 out. de 2019.
} 
ocorreu a conversão que transformou um pacato indivíduo em um gênio santificado. Para ilustrar essa transformação, Qorpo-Santo o descreve seu "renascimento" a partir de imagens que traduzam essa mudança espiritual e corpórea: "Depois de contar trinta e quatro annos de idade - entrei na barriga de huma mulher, e sahi pelo umbigo! O que acho mais interessante é - dar-lhe um beijo! (Suponho que este facto aconteceu, paraque se cumprissem as palavras de J. C.: - Para entrar no reino de Deos - haveis de nascer outra vez!)" (QORPO-SANTO, 1877, volume I, p. 154).

Logo no início do volume I da Ensiqlopédia, há uma "Introdução" na qual QorpoSanto descreve passagens importantes de sua vida, destacando fatos que ajudariam o leitor a compreender como sucedeu a vida desse ser especial e dotado de grande inteligência. Destacando histórias que envolvem seu pais, os vários cargos profissionais que ocupou e os ataques sofridos por ele, o texto que inicia esse conjunto de textos é uma exposição do escritor, o que demonstra que essa coleção terá como ponto central a figura de um homem comum que se tornou um sábio. Todos os escritos, dessa forma, giram em torno dessa persona construída por José Joaquim de Campos Leão, o Qorpo-Santo. Esse é o espaço literário em que se descreve e se ratifica a transformação do pacato professor ao gênio incompreendido. Por meio dos inúmeros textos, a figura de José Joaquim cede espaço ao personagem QorpoSanto, criando um ambiente literário difuso, que esbarra nas barreiras do que seria ou não ficcional. Fatos ou documentos "reais" são mesclados a outros tipos de escritos de natureza mais literária, criando uma organização que quebra o status do real e amplia as barreiras do imaginário.

Como já hei publicado - sabem todos o dia em que nasci, cujas minuciozidades encontram-se em meu Testamento também publicado. Começa portanto a minha vida intelectual e moral do momento em que brilhou em meu cérebro um raio de intelligencia. (...) É para mim problematico - se meu corpo era pura carne animada de hum pouco de espirito, ou se ja nele existia o Santo que na idade de trinta e quatro anos subiu ao Céu: o qual ao som de palavras que o feriram começou a desenvolver-se guiando meus passos. (...) Falecido meu pai em 1839, vim para esta cidade em 1840 estudar grammatica nacional e aplicar-me á especie de trabalho lucrativo que mais conviesse a mim e á minha família. (...) Dois annos depois habilitei-me para o magistério público, que exerci desde Junho de 1851 até Maio de 1855; deixando-o para amparar minha Mãe que se achava doente. Casando-me nesse mesmo anno nesta cidade (no dia de S. Pedro), nella fiquei leccionando em collegios. Em 1856 logo depois do cólera-morbus tomei sobre mim a direcção do collegio S. João; em 1857, por ameaçado de uma moléstia de peito - passei-me para Alegrete, onde fundei o collegio de Instrucção primaria e secundaria Alegretense. Em 1861, por molestia de pessoas da família aqui existentes regressei, provendo-se-me mezes depois na cadeira pública da freguezia de N. S. Madre de Deos; a qual 
exerci até Julho de 1862; época em que - actos violentos de que fui victima, alguns dos quaes ignorei por espaço de dois anos, com que cortarão-me todos os recursos á subsistência, - levaram-me á villa do Triunfo no $1 .^{\circ}$ de Janeiro de 1863. Foi exactamente quando começaram taes actos violentos que eu comecei tãobem a tomar notas para nesta última. Hei escripto ainda que pouco para jornaes desde 1852 até 1873 , anno em que cessei para voltar ao commercio, utilidade pública mandava imprimir, que não fosse qualificado - crime! e pelo qual - não houvesse de sofrer alguma pena! Rediji entretanto nesta cidade em 1868, e na de Alegrete em 1871 o jornal - A Justiça, por espaço de alguns mezes. O cançaço e muitos outros motivos ponderosos forçarão-me 17 mezes, a não continuar commerciante nesta cidade. (QORPO-SANTO, 1877, p. 01-02).

Refletir sobre a Ensiqlopédia compreendendo-a como um diário-literário de QorpoSanto, leva a necessidade de buscar mais informações sobre a biografia do escritor. Movimento importante, visto que há uma interferência muito grande de sua vida em seus textos. Tanto que muitos críticos leram sua vivência a partir dos seus próprios relatos e isso fez com que o tom fantasioso que impera na Ensiqlopédia adentrasse os juízos acerca da personalidade de José Joaquim e da sua convivência social. Recontar alguns fatos de sua vida por meio de documentos da época ou dos estudos críticos sobre o escritor, demonstra como ocorreram alguns fatos importantes e que são úteis ao entendimento de como o escritor se forjou dentro da dinâmica cultural na qual estava inserido. Seu contexto social influenciou seus escritos, assim como suas relações com os letrados da época. Ou seja, apesar do tom místico dado à figura de Qorpo-Santo, o homem José Joaquim tinha uma vida comum com afetos e desafetos.

José Joaquim era filho de portugueses oriundos da região dos Açores que fixaram residência na cidade de Triunfo no Rio Grande do Sul (TIBURI, 2013). O pai de QorpoSanto, Miguel José de Campos, foi um dos primeiros professores do estado do Rio Grande do Sul. Durante a Revolução Farroupilha, nas proximidades de Triunfo, "morre em 1839, seu pai de Qorpo-Santo - numa emboscada preparada por Francisco Pedro de Abreu (mais tarde Barão de Jacuí), na charqueada de Juca Leão” (SANTO, 2003, p. 19). De Miguel José, o escritor herdou a profissão e, ao que tudo indica, o apreço pelo regime monárquico.

José Joaquim casou-se com a também professora Inácia Maria no ano de 1856, na cidade de Triunfo. O casal teve quatro filhos: Idalina Carlota de Campos Leão, Lídia Marfisa de Campos Leão, Plínia Manuela de Campos Leão e Tales José de Campos Leão. Em seus escritos também constam informações sobre uma filha falecida ainda criança: 
charqueadas de São Jerônimo com o nome de Maria Jozé, existe sepultada no Cemitério desta cidade cova número 692 - em 13 de Janeiro do corrente ano (QORPO-SANTO, volume II, 1877, p. 63).

Nesse período, José Joaquim de Campos Leão se efetivou no ofício de professor de primeiras letras, passando a lecionar em diversas cidades, como Alegrete, Santo Antônio da Patrulha e Porto Alegre. Fundou os colégios São João, na capital em sociedade com Francisco Polly e o Primário e Secundário Alegretense, em Alegrete, respectivamente, nos anos de 1856 e $1857^{10}$. Há documentos que provam que José Joaquim ocupou o cargo de professor em Santo Antônio da Patrulha. Nessa cidade, o professor "bonachão" fundou, no ano de 1851, uma Loja Maçônica e um Grupo Dramático, junto com alguns habitantes da cidade, como o Tabelião José Cândido de Campos e Arceno Pinto Bandeira, este último era cunhado de Manuel Luís da Silva Borges, popularmente conhecido como General Osório (MACIEL, 1987, p.67-68).

A aparente estabilidade de sua vida foi interrompida pela doença que o acometeu no ano de 1862: a monomania ${ }^{11}$. Esse fato muda os caminhos de José Joaquim e suas relações pessoais. O escritor incorpora Qorpo-Santo ao nome e se transforma em uma figura excêntrica ${ }^{12}$. A partir do momento em que foi afastado do cargo de professor, iniciou uma nova e controversa etapa da vida de José Joaquim. Inácia, sua esposa, o acusou, juntamente com algumas autoridades da cidade de Porto Alegre, de ser incapaz de gerir o dinheiro do casal. Ao que consta nos documentos de seu inventário, possuía alguns bens de valor que lhe garantiu uma certa fortuna ${ }^{13}$. Separado da família e enfrentando as brigas para administrar seu dinheiro, escreveu textos dos mais variados gêneros. Por meio destes, criava e apresentava ao mundo (?) sua nova persona ${ }^{14}$ : o santo-gênio incompreendido.

10 CÉSAR, Guilhermino. "Qorpo-Santo no Arquivo Histórico". Correio da Manhã, Porto Alegre, 21 fev. 1976, Caderno de Sábado: "Qorpo-Santo em Outros Papéis do Arquivo". 28 fev.1976; "1862, o Ano da Crise - ou - Loucura Com Uma Pitada de Gênio". 03 mar. 1976; "Solo un Pazzo...”. 13 mar. 1976.

11 "Essa definição introduziu uma mudança na concepção de loucura, que, até então, era compreendida como falta de razão, sendo o delírio desarrazoado, a sua marca. Na monomania, por sua vez, o delírio seria apenas parcial e, por isso, a loucura perderia a visibilidade de antes, sendo necessário o olhar meticuloso do médico" (PROENÇA, 2012, p. 80).

12 De acordo com o escritor Luiz Antônio Assis Brasil, uma bisneta de Qorpo-Santo relatou que ele teria expulsado todas as mulheres de casa após um "surto", ficando apenas com o filho, Thales, um cocheiro e um cozinheiro. (GARBOGGINI, João André Britto de. Qorpo Santo - Lanterna de Fogo: compêndio dramatúrgico em parágrafos e imagens. Tese - Instituto de Artes da Universidade Estadual de Campinas, Unicamp. Campinas, 2008, 120 páginas).

${ }^{13}$ Em seu inventário, constam sete casas (em Porto Alegre e Triunfo) e um terreno (Porto Alegre), além de algumas ações da "Companhia Hidráulica" e da "Companhia de Carruagens" - o inventário encontra-se no Arquivo Público de Porto Alegre (APERS), localizado na cidade de Porto Alegre-RS.

${ }^{14}$ Acometido por perturbações mentais aos 32 anos, Qorpo-Santo passou a acreditar que seu corpo tivesse se tornado santo e que além de realizar milagres, também poderia "receber" a alma de outras pessoas vivas, em um 
No ano de 1866, Qorpo-Santo produziu as peças de teatro, gênero que o evidenciou no universo literário brasileiro do século XX. Interessante salientar que no momento da escrita dessa dramaturgia, Porto Alegre enfrentava os efeitos da Guerra do Paraguai (1864-1870) que ocasionava um clima fúnebre na cidade.

Nessa atmosfera pesada e sombria, a vida social de Porto Alegre é, a de uma cidade...morta. Suas casas de diversões estão de portas cerradas, suas sociedades bailantes e recreativas têm seus salões desertos, rareia cada vez mais frequência a seus cafés e confeitarias e nem sequer a troupe circense do aposteosado Luís Livreiro, sobejante do debandada geral, se anima a reerguer o toldo para oferecer à população um pouco de alento nessas ásperas horas de sacrifício (FERREIRA, 1956, p. 97).

Além do hiato cultural e social que a cidade enfrentava, o edifício teatral era usado como alojamento por um grupo de soldados (D’EU, 1981). A guerra ocupava, literalmente, todos os espaços, silenciando a vida social porto-alegrense. Enquanto isso, Qorpo-Santo escrevia sua dramaturgia composta, majoritariamente, por comédias. Encontrou no riso o caminho para ressignificar a morbidez que assolava as artes na cidade, assim como fez de seus relatos-pensamentos o material necessário para manter sua voz ativa. Nos anos finais da década de 60 dos oitocentos, a razão perdida e a guerra infinita assombraram suas ideias e, por meio da escrita, realçava suas ânsias, medos e convicções.

O escritor foi submetido a diversos testes psicológicos em Porto Alegre, que divergiram quanto a sua saúde mental. Na tentativa de conseguir uma avaliação médica de especialistas de fora da província, José Joaquim de Campos Leão Corpo Santo partiu para o Rio de Janeiro, em 08 de abril de 1868, como informa a relação de passageiros do vapor vindo de "Montevidéu com escalas", publicada no Correio Mercantil". Com destino a dois importantes Asilos cariocas: Hospício Pedro II, maior hospital de alienados do Brasil na época, e a Casa de Saúde Nossa Senhora d'Ajuda. O escritor permaneceu quarenta e oito dias internado para que fossem realizadas avaliações de médicos distantes da província e das querelas que o envolviam.

Os laudos médicos emitidos pelo importante médico Torres Homem ${ }^{16}$ no Rio de Janeiro e a defesa de seu advogado, Pessanha Póvoa, foram impressos por Qorpo-Santo no

processo chamado "transmigração de almas".

${ }^{15}$ Correio Mercantil, Rio de Janeiro, p. 03, 09 abr. 1868.

16 João Vicente Torres Homem, importante médico do século XIX, clinicou quase a vida inteira na Casa de Saúde de Nossa Senhora da Ajuda, local onde Qorpo-Santo também foi internado. Atuou, igualmente, em outros locais, lecionou na Faculdade de Medicina do Rio de Janeiro e foi médico pessoal do Imperador Dom Pedro II. Informação disponível em: <http://www.dichistoriasaude.coc.fiocruz.br/iah/pt/verbetes/hojovito.htm>. Acesso em 30 set. 2020. 
volume VII Ensiqlopédia ${ }^{17}$. Aliás, é importante destacar a relação entre o escritor e Pessanha Póvoa, advogado e escritor que teve um papel interessante na cena teatral da cidade de São Paulo junto aos estudantes do Largo São Francisco. Póvoa editou em 1860 a Revista Dramática, em que diversos escritores/estudantes colaboravam com peças de teatro e com discussões teóricas acerca do fazer teatral (AZEVEDO, 1981). O tempo em que esteve nos hospitais da corte, Qorpo-Santo contou com os serviços do advogado em sua defesa, além de passar alguns dias em sua casa como hóspede. Essa proximidade com um letrado atuante da época, permite perceber que o escritor, apesar dos problemas sociais que enfrentou, não era completamente apartado do convívio social.

Lembrados estarão os nossos leitores da narrativa que fizemos, há um mês e pouco mais ou menos, sobre o grave escândalo de que fora vítima em Porto Alegre, o Sr. José Joaquim de Campos Leão Corpo Santo. Este cidadão foi preso em Porto Alegre por ordem do Sr. Homem de Mello à instâncias do Dr. Fleury, e remetido como louco à corte, a fim de recolhido no hospício dos alienados. Era um bom meio do Sr. Homem de Mello descartar-se de seus inimigos, e o Dr. Fleury também interessado na perseguição, seguiu para a corte a fim de conseguir seus intentos. Agora, para que os leitores comentem como merece semelhante infâmia, leiam a seguinte carta que sobre está ocorrência nos dirigiu pessoa respeitável da corte. Ei-la: "É necessário que V. por meio das colunas do seu jornal ponha em relevo um grande serviço que o Sr. Dr. Peçanha Póvoa acaba de prestar a um cidadão e um ato de caridade a um semelhante, como um benefício a humanidade. $O$ paquete de 7 de abril trouxe daí o alferes Corpo Santo, enviado por louco, e só por um acidente salvou-se da grande trama que contra eles urdiram vis inimigos. Tendo a felicidade de encontrar no mesmo dia em que chegou no Dr. Peçanha Póvoa, que, com a maior dedicação, tratou de salvar mais essa vítima do poder corrupto. E tanto trabalhou o Dr. Póvoa que afinal o alferes Corpo Santo conseguiu-se ver-se livre do hospício. Apesar de ter daí vindo o Dr. Fleury para o homem não sair da casa dos alienados, o Dr. Póvoa conseguiu destruir toda essa maquinação tenebrosa. O Dr. Póvoa lutou muito, mas venceu e ontem o Corpo Santo saiu do hospício e hoje é hóspede de seu salvador. ("Publicações a Pedido" In. Correio Mercantil, e Instructivo, Politico, Universal. Rio de Janeiro, p.03, 05 jun. 1868 - grifo nosso).

Assim como em outra nota endereçada a seus amigos publicada pelo escritor no Jornal do Comércio do Rio de Janeiro ${ }^{18}$. Nela, mais uma vez, Qorpo-Santo se defende das acusações que buscavam seu "assassinato moral".

José Joaquim de Campos Leão Corpo Santo deixou a corte no dia 25 de junho daquele mesmo ano, como comprova a listagem de passageiros do paquete Salsipuedes, com destino à

\footnotetext{
${ }^{17}$ Nesses textos, há informações sobre sua doença, em que é possível perceber que a junta médica do Hospício Pedro II o considerou apto para viver em sociedade.

${ }^{18}$ Jornal do Commercio, Rio de Janeiro, p. 05, 07 jun. de 1868.
} 
cidade do Rio Grande publicado no Jornal do Comércio $^{19}$. Apesar de retornar à província, seu destino não era a cidade de Porto Alegre como o esperado, mas sim o Rio Grande. No mesmo periódico do mês seguinte, exatamente dezenove dias depois, em 14 de julho encontra-se o nome do escritor entre os passageiros que desembarcaram em Porto Alegre vindos de Rio Grande $^{20}$. Faltam informações que ajudem a entender o porquê Qorpo-Santo não voltou para a cidade em que residia - presume-se que o escritor mantinha boas relações com membros da maçonaria residentes em Rio Grande.

Compreender o escritor dentro da ordem maçônica, suscita questões interessantes, que favorecem o entendimento sobre a cadeia das relações sociais que Qorpo-Santo mantinha. Por meio do estudo A Maçonaria gaúcha no século XIX, de Eliane Lúcia Colussi, entende-se que tal associação foi um importante espaço para a divulgação da cultura da província, já que vários de seus membros atuavam no jornalismo e no magistério, o que lhes permitia propagar em suas áreas de atuação ideais culturais alinhados ao pensamento maçônico. Segundo a pesquisadora, "Os maçons gaúchos foram receptores de muitos elementos históricos regionais e produtores de um projeto político e cultural nem sempre bem-acabado e perceptível pela própria sociedade gaúcha" (COLOUSSI, 2003, p. 52). Pertencer à maçonaria conferia status aos seus membros, já que a ordem mantinha uma intrínseca relação com a política e, consequentemente, como o poder. Além disso, ao integrá-la, o indivíduo teria um contato maior com a cultura e o pensamento de outros lugares.

A maçonaria pode ter servido como um espaço privilegiado de homogeneização da elite gaúcha, naturalmente periférica por estar afastada dos centros decisórios mais importantes, isolada culturalmente dos polos produtores de cultura. Nesse contexto, a instituição propiciou o contato e a socialização entre os diversos segmentos da classe dominante regional, ligando o setor rural com o urbano. Ainda trouxe e difundiu informações políticas, culturais e ideológicas correntes no mundo, criando um espaço para o debate dessas questões, além de conferir status e prestígio aos seus membros por meio, entre outras estratégias, da proximidade com o poder, como, por exemplo, das nomeações a cargos políticos. (COLUSSI, 2003, p. 283).

O Parthenon Literário (1868-1885), a mais importante agremiação literária gaúcha do século XIX, tinha diretrizes mais próximas ao pensamento republicano e a maioria dos letrados que pertenciam a tal agremiação eram, em sua maioria, maçônicos. Já Qorpo-Santo, apesar de pertencer a essa ordem, mantinha ideais monarquistas.

${ }^{19}$ Correio Mercantil, Rio de Janeiro, p. 03, 25 jun. de 1868.

20 Jornal do Commercio, Porto Alegre, p. 03, 14 de jul. de 1868. 


\begin{abstract}
A Sociedade Partenon Literário foi, sem dúvida, a principal agremiação cultural do Rio Grande do Sul do século XIX, sendo considerado o órgão que efetivamente formou e consolidou um sistema literário na então Província sulina, por meio, especialmente, da publicação de uma revista mensal, que circulou de 1869 a 1879, com interrupções, contando com os grandes escritores gaúchos do momento, como Apolinário Porto Alegre, Caldre e Fião, Bernardo Taveira Júnior, Múcio Teixeira. Não se pode esquecer, igualmente, das ações extraliterárias que a agremiação partenonista organizava, inovadoras para a época, como a manutenção de aulas noturnas e a realização de saraus poético-musicais em que se procedia à alforria de escravos" (PÓVOAS, 2009, p. 70).
\end{abstract}

Não há informações exatas que permitam inferir com exatidão os motivos do distanciamento entre Qorpo-Santo e a agremiação que reuniu, praticamente, todos os escritores da província do Rio Grande do Sul. Porém, as ideias políticas do escritor não se encaixavam ao que era defendido pela maioria dos letrados que pertenciam ao Parthenon, essa diferença pode ter sido o impeditivo para que ele transitasse em tal círculo literário.

Mesmo preterido do mais importante movimento literário de seu meio social, QorpoSanto manteve sua verve jornalística e artística. No ano de 1871 editou na cidade de Alegrete um periódico intitulado A Justiça, em que escreveu sobre os mais diversos assuntos: política, os problemas estruturais e a vida social de Porto Alegre, poemas, textos produzidos durante sua estada na corte, correspondências enviadas às autoridades do Rio Grande do Sul etc. Não existem informações exatas sobre o tempo de funcionamento desse veículo e se existiam outras pessoas envolvidas na sua confecção. Contudo, segundo textos da Ensiqlopédia, o periódico mantinha um número de assinantes (Ensiqlopédia, volume II - "A Justiça", 1877, p. 39) e foi elogiado pelo periódico do Rio Grande $A$ Sentinela do Sul, que enfatizou que " $A$ Justiça só faz justiça".

Como já exposto, em 1877, Qorpo-Santo reuniu todos os seus escritos para organizar a Ensiqlopédia ou Seis Mezes de huma Enfermidade. Um ano após ser publicada, em 1878, a obra foi citada pelo recém fundado periódico Álbum de Domingo, que era formado por jornalistas pertencentes ao Parthenon Literário. Defensor das estéticas modernas, como parnasianismo e naturalismo, Álbum de Domingo foi o único local que teceu críticas a obra de Qorpo-Santo.

(...) na coluna "A Semana" do dia 12 de junho de 1878, a Ensiqlopédia foi apontada ironicamente como uma obra que serviria para instruir: "Quem quiser educar as filhas, com bons princípios e moral, dê-lhes ler Teófilo [sic] Gautier ou Paulo de Kock; Quem for amante da leitura instrutiva, amena, criteriosa e sensata compre os livros de Corpo Santo" (Álbum de Domingo, 1878 , p. 46). A crítica elenca ironicamente as "serventias" de algumas obras, como os livros de Theóphile Gautier e Paul de Kock, considerados imorais e, 
por isso, com serventia à educação feminina. No caso de Qorpo-Santo, a estrutura da Eniqlopédia, bem como as ideias nela contida, são adjetivadas como "amena, criteriosa e sensata". Ou seja, exatamente o contrário do que se pensava da obra à época. Tal apreciação pode ter corroborado para o rótulo negativo que os textos de Qorpo-Santo receberam por parte dos letrados sulinos. Essa crítica pode ser um reflexo do menosprezo de outros escritores para com a obra literária qorpo-santense. (GONÇALVES, 2018, p. 178-179)

Na História Popular de Porto Alegre, o jornalista e escritor Achylles Porto Alegre, figura importante na cena literária gaúcha do século e um dos fundadores do Parthenon Literário, publicou uma crônica sobre Qorpo-Santo, juntamente com outros relatos sobre locais e personagens importantes à memória da cidade.

Foi uma espécie de Dom Quixote. Atacava primeiro moinhos de vento do jornalismo, contando ali encontrar um estupendo El Dourado. Quebrou lanças mortalmente. A sua Justiça passou desapercebida para o público, mas pesada para ele: levou-lhe um par de conto de réis. Dom Quixote, porém, não desanimou: voltou-se para a poesia. Aqui já não atacou moinhos, mas cata-ventos: foi como se quisesse meter no bolso uma rajada de vento ou tecer com raios de sol uma corrente para o relógio. Fracassou também.

Só Napoleões vencem o impossível.

Daí em diante, Qorpo-Santo foi de desilusão em desilusão, de queda em queda, e desapareceu envolto numa capa de ridículo, porque foi um Dom Quixote sem Dulcinéia.

E sem amor real ou platônico, de Julieta ou Dulcinéia, a vida é estéril, apagada, e inútil - porque, como disse o poeta, o amor é a vida da terra, a luz do sol e o sol da vida. (PORTO ALEGRE, 1994, p. 198).

Achylles elenca as frustrações de Qorpo-Santo em um relato que o compara ao sonhador e insano personagem de Cervantes. Destacando que todas suas empreitadas, literárias e amorosas, foram inúteis, tornaram-no ridiculamente frágil. Assim terminou seus dias, segundo os olhares de seus coetâneos, frustrado e sozinho. Apenas o cigarro o acompanhou nesses tempos finais, causando uma tuberculose que ceifou sua vida no dia 01 de maio de 1883. Não tem como mensurar o quanto há de verdade no relato de Achylles sobre os dias finais do escritor, mas em uma coisa o jornalista se equivocou: Qorpo-Santo não desapareceu. Pelo contrário, tornou-se um escritor mais debatido do que aqueles que o ostracizaram. Seus escritos, por fim, o transformaram em um ser eterno.

\section{REFERÊNCIAS BIBLIOGRÁFICAS}

\section{FONTES PRIMÁRIAS}


Correio da Manhã (Rio de Janeiro)

Correio do Povo (Porto Alegre, Rio Grande do Sul)

Diário do Rio de Janeiro (Rio de Janeiro)

Diário de Notícias (Porto Alegre, Rio Grande do Sul)

Jornal do Commercio (Porto Alegre, Rio Grande do Sul)

Jornal do Commercio (Rio de Janeiro)

O Mercantil (Porto Alegre, Rio Grande do Sul)

Relatórios dos Presidentes das Províncias Brasileiras: Império - 1830 a 1889 (Rio Grande do Sul)

\section{OBRAS DE QORPO-SANTO}

QORPO-SANTO, José Joaquim de Campos Leão. As relações naturais e outras comédias. Fixação do texto, prefácio e notas por Guilhermino César. 2 ed. Porto Alegre: Movimento/IEL/UFRGS, 1976. (Teatro Brasileiro, 2).

. Miscelânea Quriosa. ESPIRITO SANTO, Denise (org.). Rio de Janeiro: Editora

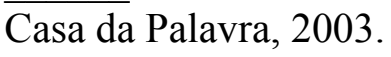

2000

Poemas. ESPIRITO SANTO, Denise (org.). Rio de Janeiro: Contra Capa Livraria,

Teatro completo. Apresentação de Eudinyr Fraga. São Paulo: Iluminuras, 2001.

. Ensiqlopédia ou Seis Mezes de huma Enfermidade. Disponível em: www.pucrs.br/biblioteca/qorposanto. Acesso em: 18 out. de 2020.

\section{OUTRAS REFERENNCIAS}

ALMEIDA, Júlia Aschermann Mendes de. O conceito de máxima e sua importância para a Filosofia moral de Immanuel Kant. 128 p. [dissertação].Florianópolis-SC: Universidade Federal de Santa Catarina, 2009.

AZEVEDO, Elizabeth R. Um Palco sob as Arcadas: o teatro dos estudantes de Direito do Largo de São Francisco, em São Paulo, no século XIX. São Paulo, Annablume, 2000.

CAMARGO, Ana Maria de Almeida (org.) Revista Dramática: São Paulo, 1860 - ed. facsimilar. São Paulo: Editora da Universidade de São Paulo, 2007.

CAROZZI, Silvana. O Qorpo-Santo da escrita: o projeto ensiqlopédico de José Joaquim de Campos Leão. 2008. 135 p. Dissertação (Mestre) - Faculdade de Letras, Universidade Federal de Minas Gerais, 2008, 135 páginas. 
COLUSSI, Eliane Lucia. A maçonaria gaúcha no século XIX. UPF Editora: Passo Fundo, 2003.

DARTON, Robert. O Iluminismo como negócio: história da publicação da Enciclopédia (1775-1800). São Paulo: Companhia das Letras, 1996.

D’EU, Conde. Viagem Militar ao Rio Grande do Sul. Belo Horizonte: Ed. Itatiai; São Paulo: Ed. da Universidade de São Paulo, 1981.

FERREIRA, Athos Damasceno. Palco, salão e picadeiro em Porto Alegre no século XIX. Porto Alegre: Globo, 1956.

FOUCALT, Michel. "Linguagem e Literatura". In. MACHADO, Roberto. Foucalt, a filosofia e a literatura. Rio de Janeiro: ZAHAR, 2005, p-p. 147-173.

GARBOGGINI, João André Britto de. Qorpo Santo - Lanterna de Fogo: compêndio dramatúrgico em parágrafos e imagens. Tese - Instituto de Artes da Universidade Estadual de Campinas, Unicamp. Campinas, 2008, 120 páginas.

GONÇALVES, Maria Clara. Cenas de um mundo às avessas: as relações entre a dramaturgia de Qorpo-Santo e o teatro brasileiro oitocentista. 202 p. (Tese de doutorado). Campinas-SP: Universidade Estadual de Campinas, Instituto de Estudos da Linguagem, 2017.

Revisitando a dramaturgia de Qorpo Santo em seu contexto original. Sala Preta, São Paulo, v. 18, n. 1, p. 168-180, 2018. Disponível em: http://www.revistas.usp.br/salapreta/article/view/138390. Acesso em: 08 out. de 2020.

JUNIOR, José Maciel. Reminiscências da minha terra: Santo Antônio da Patrulha. Porto Alegre: Editora: Escola Superior de Teologia e Espiritualidade Franciscana, 1987.

MARICÁ, Marquês (Mariano José Pereira da Fonseca). Máximas, Pensamentos e Reflexões. São Paulo: eBooksBrasil.org, 2006. Disponível em: http://www.ebooksbrasil.org/eLibris/marica.html. Acesso em: 10 de ago. de 2019.

PEDROSA, Fernando Alberto Gomes. "As três confrarias marítimas de Seismbra num Regimento de 1563”. Revista Vox Musei: arte e patrimônio. 2014. Vol.02, p.72-83.

PROENÇA, Emanuele Luiz. Qorpo-Santo: pelos (des)caminhos da loucura no Brasil do século XIX. Dissertação - Universidade Federal do Espírito Santo. Vitória-ES, 2012, 114 páginas.

PORTO-AlEGRE, Achylles. História Popular de Porto Alegre. Porto Alegre: EU/Porto alegre, 1994.

PÓVOAS, Mauro Nicolas. "Fontes primárias e dúvidas literárias: o caso Murmúrios do Guaíba”. In: Revista Iluminart. Sertãozinho, SP, n. 1, p. 69-76, 2009.

REMOR, Carlos Augusto Monguilhott. A nobreza das maximas: do marques ao Barão. 193 p. Dissertação (Mestre) - Universidade Federal de Santa Catarina, Florianópolis-SC, 1995. 
TIBURI, Margarida. Charqueadores, Estancieiros e Vereadores: Elites Econômicas e Política. Ribeirão Preto (SP): Editora Nova Conceito, 2013.

Recebido: $15 / 10 / 2020$

Aprovado: 02/03/2021 